\title{
O ESTADO DA ARTE DA TEMÁTICA DA EDUCAÇÃO AMBIENTAL NO ENSINO DE CIÊNCIAS NO ENSINO FUNDAMENTAL
}

\author{
DÉBORA DE ARAUJO BASTOS ${ }^{1}$
}

DANIELE SAHEB ${ }^{2}$

\section{RESUMO}

Esta pesquisa do tipo estado da arte tem por objetivo analisar a abordagem da Educação Ambiental no ensino de Ciências, no período dos anos finais do Ensino Fundamental, no Brasil, a partir de artigos extraídos das Bases de dados SCIELO e REDALYC, com a seleção entre os anos de 2010 a 2019. Foram encontrados artigos dentro desse assunto, com abordagens distintas do ambiente escolar, sendo usados apenas aqueles dentro do ensino, pois o foco do estudo é compreender como a educação ambiental é praticada no meio escolar. Ao fim foram selecionados 41 artigos, que tratavam do assunto em questão, a Educação Ambiental na prática escolar, para análise final e compreensão do que vem sendo abordado no meio acadêmico dentro da Educação Ambiental, com foco nos anos finais do Ensino Fundamental nas Escolas brasileiras.

PAlAVRAS-CHAVE: Educação Ambiental; Ciências; Ensino Fundamental; Prática Docente.

\begin{abstract}
This state-of-the-art research aims to analyze the approach of Environmental Education in Science teaching, in the period of the final years of Elementary Education in Brazil, from articles extracted from the SCIELO and REDALYC databases, with the selection between the years from 2010 to 2019. Articles were found within this subject, with different approaches to the school environment, being used only within teaching, as the focus of the study is to understand how environmental education is practiced in the school environment. At the end 41 articles were selected, which dealt with the subject in question, Environmental Education in school practice, for final analysis and understanding of what is being addressed in the academic environment within Environmental Education, focusing on the final years of Elementary Education in Brazilian Schools.
\end{abstract}

KEYWORDS: Environmental education; Sciences; Elementary school; teaching practice

\footnotetext{
${ }^{1}$ Pontifícia Universidade Católica do Paraná. E-mail: debora.araujobastos@gmail.com

${ }^{2}$ Pontifícia Universidade Católica do Paraná. E-mail: daniele.saheb@pucpr.br
} 


\section{INTRODUÇÃO}

Sabe-se que a questão ambiental envolve o fato da falta de sensibilização e interação do homem com a natureza, do entendimento de que ela está ali para servi-lo com seus recursos naturais. Pois para atender às necessidades diárias humanas, -- o que cada um consome de recursos naturais, em ações, naquilo que é retirado, consumido e descartado sem nenhum controle --, o equilíbrio ecológico é alterado, pois como cita Morin “o homem está na natureza e a natureza está no homem" (2005, p.71).

Essa é uma característica não somente das empresas e indústrias, mas sim, de cada ser humano em seu cotidiano, que colabora para esta degradação. Falta assim, uma conexão do meio ambiente e com a sociedade, sendo preciso pensar nessa questão ambiental mais como uma questão socioambiental.

É nessa abordagem que o valor das atividades pedagógicas é compreendido como um fator que atua no desenvolvimento de um pensamento crítico por parte dos alunos. Nos últimos anos, as questões ambientais têm ocupado lugar de destaque nas preocupações mundiais, colocando assim a educação como um fator muito importante no combate à depredação do meio ambiente, para o desenvolvimento de mentes conscientes.

Dentro da perspectiva ambiental existem ferramentas para que o aluno possa compreender problemas que afetam a sua vida, a de sua comunidade, e de seu país e a do planeta, passando assim para uma perspectiva de educação planetária. Muitas das questões, que na maioria das vezes não são relacionadas ao meio ambiente como as políticas, econômicas e sociais são permeadas por elementos diretamente ligados à questão ambiental.

Nesse sentido, as práticas de aprendizagem devem se organizar de maneira a criar oportunidades para que o aluno possa usar o conhecimento sobre o meio ambiente para entender a sua realidade e atuar sobre ela, no modelo do ensino formal que "...orienta-se, essencialmente, se não exclusivamente, para o aprender a conhecer e, em menor escala, para o aprender a fazer" (DELORS, 2001). Dentro da prática pedagógica e curricular, o trabalho de educação ambiental deve ser desenvolvido a fim de ajudar os alunos a desenvolver uma sensibilidade em sua consciência, sobre as questões relativas ao meio para que possam assumir posições afinadas com os valores referentes à sua proteção e melhoria.

Uma questão importante a ser levantada é sobre essas questões ambientais, que tradicionalmente são tratadas no ensino de ciências, ou seja, as práticas pedagógicas dos professores de ciências quando abordam a temática da educação ambiental no ensino fundamental. Como cita a autora Carvalho, "quando falamos em meio ambiente, muito frequentemente essa noção logo evoca as ideias de 'natureza', 'vida biológica', ‘vida selvagem', 'flora e fauna.”' (2012, p. 35), e com isso quando se é trabalhado o assunto da educação ambiental que envolve o meio ambiente em seus 
assuntos, a responsabilidade, na maioria das vezes se torna do professor de ciências, por ter a formação na área.

A prática do ensino de ciências é uma das formas de ajudar na elaboração do aprendizado, usando recursos que auxiliem o estudante a desenvolver a capacidade de pensar, criticar e refletir, sobre a temática ambiental, já que a escola e o professor atuam com papéis fundamentais no desenvolvimento do estudante, pois ambos causam influência, amadurecendo as habilidades sociais do educando. Com isso, os professores de ciências contribuem com a compreensão dos transtornos causados no planeta, como por exemplo, o aquecimento global, o desmatamento, e buscam conscientizar os alunos com uma forma mais participativa, na busca de soluções urgentes para esses problemas.

São esses os problemas que fazem parte da vida de estudantes e professores, em seus cotidianos. Por isso, a importância de trabalhar abordando os assuntos ambientais como propõem os parâmetros de ciências naturais, isto é, de forma contextualizada. E não abordar apenas o meio ambiente, mas sim, colocar de uma maneira mais reflexiva e crítica, desenvolvendo esse assunto em sala de aula. No entanto, o desenvolvimento da educação ambiental ainda é muito restrito, limitando seu objetivo principal de compreender o ambiente de forma global. Consequentemente, a rede de interrelação pessoa-sociedade-natureza (que é o centro da educação ambiental) é percebida somente parcialmente (SATO, SAUVÉ, 2005).

Podemos dizer que a relação do meio ambiente com a educação pensando na cidadania cria um papel com cada vez mais desafios, com urgência de novos saberes e práticas, para aprender os processos que se tornam cada vez mais complexos, tendo como principal eixo norteador da educação ambiental a busca pela solidariedade, igualdade e respeito à diversidade, com uma prática com mais diálogos e interação entre docentes e discentes. É preciso pensar em mudanças nas atitudes, que busquem o equilíbrio.

Sobre a educação ambiental na abordagem formal, considera-se a preocupação com o desenvolvimento de novas práticas, sendo estas mediadas dentro dos saberes relacionados ao meio ambiente, permitindo a construção de habilidades e conhecimentos. Nesse sentido, propõem-se as três esferas multidimensionais dentro da educação ambiental, que o autor Loureiro (2006) aborda: "o indivíduo, a sociedade e a natureza".

Penteado (2010, p. 55) afirma que a educação ambiental, "trata-se de uma tarefa a ser cultivada desde os primeiros anos de escolaridade". Trabalhar com alunos do ensino fundamental gera a oportunidade, desde o começo, de estarem em contato com a educação ambiental. E a abordagem nos conceitos dessa temática dentro dos conteúdos de ciências é uma alternativa que atrela o conteúdo da sala de aula com a vivência do educando. 
Com isso, é preciso pensar que a educação ambiental caminha em direção a compreender as relações sociedade-natureza e descobrir como intervir sobre os problemas e conflitos ambientais.

Com a análise sobre a temática e a problematização para a realização do estudo de revisão, foi preciso reconhecer quais seriam os melhores descritores para a busca nos bancos de dados. Como a temática central é a educação ambiental, esse foi o primeiro descritor escolhido. O segundo foi ciências, pois a busca se reduzia a essa disciplina nas escolas, de como a temática ambiental é abordada pelos professores dessa disciplina. Com o segundo descritor escolhido, e como a busca focava nos docentes, o terceiro descritor foi a prática docente e por último ensino fundamental, para assim delimitar a faixa etária do estudo. No final foram quatro descritores (palavras-chave) escolhidas para a pesquisa.

\section{DESENVOLVIMENTO}

O estado da arte é um método de pesquisa que se realiza por meio de uma revisão bibliográfica sobre a produção de uma temática específica em um campo de conhecimento. As características desse modelo de estudo devem ser observadas ao se desenvolver uma pesquisa com essa metodologia, como o tempo e o espaço em que os estudos foram desenvolvidos. Outra característica é a temática, pois serve para determinar e demarcar o que se busca mapear, possibilitando aos pesquisadores realizarem análises profundas, ou um panorama extenso sobre uma temática específica.

A definição das fontes em que serão feitos os levantamentos é importante para dar confiabilidade ao trabalho. É necessário também ser definida a forma como serão levantadas as referências, pois delimita e norteia as buscas levando já a uma seleção e exclusão/inclusão do que não será necessário. Geralmente essas procuras dão-se por palavras-chave nos trabalhos completos ou nos títulos e resumos, porém pode ocorrer de, ao eleger as palavras, algumas referências que abordam as temáticas em estudo deixarem de ser catalogadas por não apresentarem a palavra de busca.

Buscando-se realizar uma revisão bibliográfica sobre pesquisas do tipo estado da arte em Educação Ambiental dentro da Ciências no ensino fundamental, procurou-se identificar os artigos publicados em periódicos científicos (SCIELO e REDALYC) nos últimos dez anos, sendo este o recorte temporal, desde o ano de 2010 ao ano de 2020, recorte muito recente e que abrange muitos estudos que ainda estão em andamento.

O intuito foi realizar a verificação e discussão das características e tendências gerais dos artigos que revisam a abordagem da temática ambiental, mas por ser um tema bastante amplo, no caso deste estudo foi a área da educação o enfoque da pesquisa. 
· Sobre a elaboração da temática do estudo, fixou-se em Educação Ambiental no ensino de Ciências no ensino fundamental, com ênfase na prática docente.

Após a decisão do tema a ser estudado, foi feita a elaboração da questão de pesquisa para desenvolvimento do estudo, importante momento, para que a pergunta fosse bem elaborada. Para o tipo de estudo estado da arte, a pergunta foi formulada como: "Quais temáticas são abordadas nas pesquisas em Educação Ambiental no contexto do ensino de Ciências no Ensino Fundamental?’”.

Depois da elaboração da questão de pesquisa, foi realizada a etapa de validação da existência de estudos com a mesma temática que a questão de pesquisa propõe. A validação foi feita nas plataformas PICo e Scielo, para a busca de outros estudos similares. Validação realizada, com a conferência nas plataformas, para ver se não existia outro estudo tipo estado da arte com a mesma temática que o que eu pretendo escrever, não foi encontrado nenhum trabalho desse modelo com essa temática, então a validação foi concluída com êxito.

Com isso, a partir dessa validação da temática abordada em um estado da arte, foi mantida a pergunta de pesquisa fixa em: "Quais temáticas são abordadas nas pesquisas em Educação Ambiental no contexto do ensino de Ciências no Ensino Fundamental?”.

Com a temática, questão de pesquisa finalizada, a próxima etapa foi a elaboração das palavras-chave (descritores) para a busca, que foram as seguintes: Educação Ambiental; Prática Docente; Ciências; Ensino Fundamental.

Com os descritores selecionados, foi possível dar início a busca nos Bancos de Dados, nas plataformas SCIELO e REDALYC. Durante a busca foi utilizado o AND entre os descritores, e o uso das aspas para os descritores duplos. A palavra Educação Ambiental foi a palavra "guia". Por ser o tema principal do meu estudo, usei-a em todas as pesquisas.

A primeira plataforma em que a busca foi realizada foi a SCIELO, primeiro com a busca com as quatro palavras-chave (descritores) selecionadas e o resultado foi nenhum artigo encontrado.

A partir disso decidiu-se realizar a pesquisa usando como descritores nas buscas Educação Ambiental junto aos outros descritores, separando as buscas em pares e trios.

1. Realizei a busca somente com a palavra "Educação Ambiental" e foram encontrados 481 artigos, nos quais foi utilizado o filtro de período de publicação, abarcando os anos de 2010 a 2020, e assimo resultado foi reduzido para 310 artigos.

2. O primeiro par selecionado foi "Educação Ambiental" e "Prática Docente" com resultado de 4 artigos. 
3. O segundo par selecionado foi "Educação Ambiental" e "Ensino Fundamental", o qual não obteve muito sucesso, sendo o resultado de 38 artigos após uso do filtro de período reduzido para 22 artigos.

4. O terceiro par selecionado foi "Educação Ambiental" e Ciências no qual o resultado de busca foram 47 artigos, com o período selecionado reduzido para 30 artigos.

TABELA 1- SCIELO COM AS INFORMAÇÕES ORGANIZADAS DOS DADOS ENCONTRADOS:

\begin{tabular}{c|c|c}
\hline Descritores & $\begin{array}{c}\text { Resultados sem o uso } \\
\text { de filtro }\end{array}$ & $\begin{array}{c}\text { Resultados com o uso de filtro } \\
\text { (ano 2010 a 2020) }\end{array}$ \\
\hline $\begin{array}{c}\text { Educação Ambiental + Ciências + Prática Docente } \\
+ \text { Ensino Fundamental }\end{array}$ & 0 & 0 \\
\hline Educação Ambiental & 481 & 310 \\
\hline Educação Ambiental +Prática Docente & 4 & 4 \\
\hline Educação Ambiental Ambiental + Ensino Fundamental \\
+ Ciências
\end{tabular}

Fonte: elaboração própria.

No final da primeira busca dos artigos, na plataforma da SCIELO, foram encontrados um total de 570 artigos, após o uso do filtro de período, de 2010 a 2020, foi reduzido a 366 artigos no total.

A segunda pesquisa foi na plataforma REDALYC, e trouxe os seguintes resultados:

1. Com a palavra "Educação Ambiental" entre aspas foi encontrado um resultado inicial de 106.122 artigos, e após aplicar os filtros de anos de publicação (2015 a 2020) e de língua portuguesa, reduzido para 736 artigos.

2. Outra combinação foi "Educação Ambiental" e "Ciências": encontrados 130.003 artigos com o uso dos filtros de anos de publicação (2015 a 2020) e de língua portuguesa, reduzido a 618 artigos. 
3. Outra combinação foi "Educação Ambiental", "Ciências" e "Prática Docente", e foram encontrados 180.323 artigos, e com o uso dos filtros de anos de publicação (2015 a 2020) e de língua portuguesa, reduzidos para 74 artigos.

4. A última combinação que fiz, foi "Educação Ambiental", "Ciências". "Prática Docente" e "Ensino Fundamental", foram encontrados 249.628 artigos, e com o uso dos filtros de anos de publicação (2015 a 2020) e de língua portuguesa, reduzidos para 45 artigos.

\section{TABELA 2 - REDALYC COM AS INFORMAÇÕES ORGANIZADAS DOS DADOS} ENCONTRADOS:

\begin{tabular}{|c|c|c|}
\hline Descritores & Resultados sem uso de filtro & $\begin{array}{l}\text { Resultado com o uso dos } \\
\text { filtros. }\end{array}$ \\
\hline "Educação Ambiental" & 106.122 & 736 \\
\hline "Educação Ambiental" AND Ciências & 130.003 & 618 \\
\hline $\begin{array}{c}\text { "Educação Ambiental” AND “Ciências" AND } \\
\text { "Prática Docente" }\end{array}$ & 180.323 & 74 \\
\hline $\begin{array}{c}\text { "Educação Ambiental" AND Ciências AND "Prática } \\
\text { Docente" AND "Ensino Fundamental" }\end{array}$ & 249.628 & 45 \\
\hline TOTAL de artigos encontrados & 666.076 & 1.473 \\
\hline
\end{tabular}

Fonte: elaboração própria.

No total dessa busca foram encontrados 666.076 artigos, após o uso do filtro de período, de 2015 a 2020, e o uso da língua portuguesa reduziu a 1.473 artigos no total.

Todas as buscas foram realizadas mais de uma vez para a conferência dos valores encontrados. (Conferência realizada nos meses de maio e junho de 2020)

O uso dos filtros foi necessário, devido aos resultados iniciais das buscas terem obtido quantidade muito grande de artigos (como é possível ver acima), e para filtrar a busca decidi usar apenas artigos realizados no Brasil para saber como está sendo trabalhada a temática ambiental nas escolas dentro do País, e quanto aos anos, decidi fazer uma análise de artigos mais recentes, para analisar qual a abordagem usada na Educação Ambiental. Será algo para colocar no artigo o fato de que há a redução do número de publicações quando se trata desse assunto na língua portuguesa e como foram reduzidas as produções nos últimos anos. 
Sendo assim foram definidos os critérios de inclusão e exclusão, para a continuidade do estudo, e para definir esses critérios foram usadas as seguintes características:

Critério de inclusão e suas características:

- Prática docente dos professores de Ciências na Educação Ambiental;

- Abordagem da temática Educação Ambiental na escola;

- Prática no Ensino fundamental;

- Educação Ambiental no ensino de Ciências;

- Período de publicação 2010 para cima;

- Estudos realizados no Brasil.

Critérios de exclusão e suas características:

- Outras disciplinas como Geografia, física não entram no estudo;

- Educação Ambiental abordada em turismo, ou qualquer outra área que não seja escolar;

- Estudo feitos no ambiente escolar que não seja da educação básica (exemplo universidades);

- Abaixo do ano 2010;

- Línguas estrangeiras e de outros países.

Durante a busca dentro das plataformas de base de dados, SCIELO e REDALYC, foram encontrados alguns resultados, como foi possível ver nas tabelas demonstradas na metodologia, com isso as próximas etapas foram as seguintes:

- Elaboração das tabelas no EXCEL, com diferentes abas, para diferentes combinações de palavras-chave e base de dados usados.

- Na base SCIELO, foi realizada a importação dos dados de maneira mais prática, pois o site disponibiliza uma opção para importar e salvar uma tabela em EXCEL. Apenas foram feitas 4 abas com as combinações usadas para pesquisar, e, no fim, todas foram juntadas em uma única tabela da SCIELO, na qual, foi dado o nome da aba de "SCIELO formatizada".

- Para inserir as informações sobre a pesquisa feita da base de dados REDALYC, primeiro foi copiado o conteúdo do site no modo tabela e inserido no EXCEL. Como não vem organizado, foi necessário eliminar os ícones desnecessários e organizar apenas as informações importantes e úteis. Foram feitas 4 abas com as combinações e uma com todas juntas apenas na base REDALYC, que recebeu o nome de "REDALYC formatizada".

- No fim, foram juntadas a tabela da SCIELO e da REDALYC com todos os títulos encontrados, sem eliminar nenhum, com o nome da tabela de SCIELO e REDALYC Ok. 
- Após a junção das duas bases (SCIELO E REDALYC), foi realizada a busca pelos títulos duplicados, com a ferramenta que o EXCEL concede. Após essa investigação foram encontrados muitos títulos repetidos entre as bases e alguns dentro da mesma base, que nesse caso selecionei como um problema.

- Foram feitas as seguintes marcações: S para duplicados; $\mathrm{N}$ para não duplicados e P para aqueles com problema como dois títulos iguais na mesma base/busca.

\section{TABELA 3 - TÍTULOS DUPLICADOS}

\begin{tabular}{c|c|c|c}
\hline $\begin{array}{c}\text { Títulos } \\
\text { Duplicados }\end{array}$ & SCIELO & REDALYC & Iguais em Ambas as bases \\
\hline & 64 & 868 & 34 \\
\hline
\end{tabular}

Fonte: elaboração própria.

Sobre as duplicatas encontradas é preciso explicar algumas características encontradas dentro da tabela, devido à união das pesquisas com os diferentes descritores (4 pesquisas diferentes em cada base, mas o descritor educação ambiental sempre esteve presente). Apareceram algumas duplicadas nas mesmas bases, mas também ocorreram duplicadas dentro de uma mesma busca.

Dentro da pesquisa realizada apenas na base SCIELO:

- Foram encontradas 64 duplicadas no total;

- 44 que se duplicaram na revista;

- Devido ao descritor "Educação Ambiental" aparecer em todas as buscas, aconteceu de um mesmo artigo aparecer 3 vezes na mesma busca;

- E com duplicatas com a outra base foram 34 artigos que aparecem iguais nas pesquisas de ambas as bases;

- Foram eliminados após essa análise 64 artigos da base SCIELO;

- Após a exclusão dos duplicados ficaram 302 artigos para análise.

Dentro da pesquisa na REDALYC:

- Foram encontrados 868 duplicadas no total;

- Foi possível registrar também assim como na base da SCIELO a repetição de mais de duas vezes de um mesmo artigo, por isso um número tão elevado de duplicatas. Em alguns casos, o mesmo artigo apareceu quatro vezes, provavelmente devido ao uso combinado em todas as pesquisas do descritor "Educação Ambiental";

- Duplicados em comum com a base SCIELO foram 34 artigos;

- Foram eliminados os 868 artigos duplicados; 
- Após a exclusão dos duplicados ficaram 605 artigos para análise.

Após essa análise, foi realizada a "limpeza", criando assim no EXCEL uma nova aba/tabela com todos os artigos, e nessa tabela de limpeza foram eliminados os duplos. Com a eliminação ficaram artigos: 907 artigos, para a análise. Na próxima etapa, foi criada uma aba/tabela para classificá-los conforme o tema de pesquisa, mas sem excluir nenhum, usando as seguintes regras para classificá-los:

- Colunas na frente dos títulos dos artigos para classificá-los:

- As colunas foram: Educação Ambiental+ Ciências (EF) e Educação Ambiental+ Prática Docência.

- Outra característica foi a abordagem apenas da Educação Ambiental, e não apenas educação, ou ambiental separado levando os artigos para a área de legislação ambiental, ou ciências como ciências sociais, políticas, entre outros.

- Essas regras foram usadas na análise do título, palavras-chave e o resumo dos artigos, para uma melhor compreensão do que o artigo abordava.

Depois de realizar a exclusão daqueles que não se encaixam, dos 907 artigos sobraram 114, ou seja, foram excluídos 793 artigos, no qual o título, as palavras-chave e os resumos não possuem nenhuma similaridade com a temática da pesquisa, pois quando se busca o tema educação ambiental, aparecem muitos artigos com atividades referentes ao turismo, ambiente corporativo e poucos ligados a escola e ao ensino de ciências.

Realizada assim toda essa pesquisa e eliminação daqueles artigos onde os critérios de inclusão não se encaixavam, foi obtida a informação de que era preciso desconsiderar os artigos que foram publicados esse ano, pois o ano de 2020 ainda está em fase de atualização. Como a pesquisa ia até o ano atual, foram excluídos os artigos com essa data de publicação: foram eliminados apenas 2 artigos, restando assim 112 artigos no final para o início da análise mais detalhada.

Foi realizada a análise com foco no artigo completo (pois quando se faz um estudo do tipo estado da arte com artigos científicos é necessário analisá-los por inteiro), para compreender se o mesmo abordava a temática selecionada, sempre com os critérios de inclusão e exclusão sendo analisados.

A análise foi realizada, sem o uso de programas de análise de dados, apenas o uso do EXCEL, mas com o rigor e cuidados metodológicos que uma revisão desse tipo solicita. Foi realizada a leitura de todos os artigos, para assim buscar os itens de inclusão da pesquisa. Aqueles que não se encaixavam nessas características eram eliminados da pesquisa. 
Conforme a análise foi sendo realizada, foi percebido que alguns artigos abordavam a temática ambiental fora do ambiente escolar, e outros abordavam a educação ambiental na política, todos os itens colocados como critérios de exclusão.

No fim após muita leitura e muito rigor na análise dos artigos, com o uso dos itens de inclusão e exclusão foram eliminados 71 artigos, restando assim 41 artigos para uso no estudo e elaboração do artigo de estado da arte com a temática de educação ambiental no ensino de ciências e a questão pesquisa: "Quais temáticas são abordadas nas pesquisas em Educação Ambiental no contexto do ensino de Ciências no Ensino Fundamental?".

Os resultados encontrados na realização do estado da arte foram os seguintes:

- Foram encontrados no início desta pesquisa um total de 1.839 artigos.

- Duplicados um total de 932 artigos, sendo esses mesmos eliminados.

- Restaram 907 artigos após a eliminação dos duplicados, para realização da análise do título, palavras-chave e resumo do artigo dentro dos descritores selecionados e dos itens de inclusão e exclusão.

- Separação dos artigos por temas abordados, antes da eliminação na primeira análise após a eliminação das duplicadas.

\section{GRÁFICO 1: ARTIGOS QUE RESTARAM APÓS DUPLICATAS E SERÃO ANALISADOS}
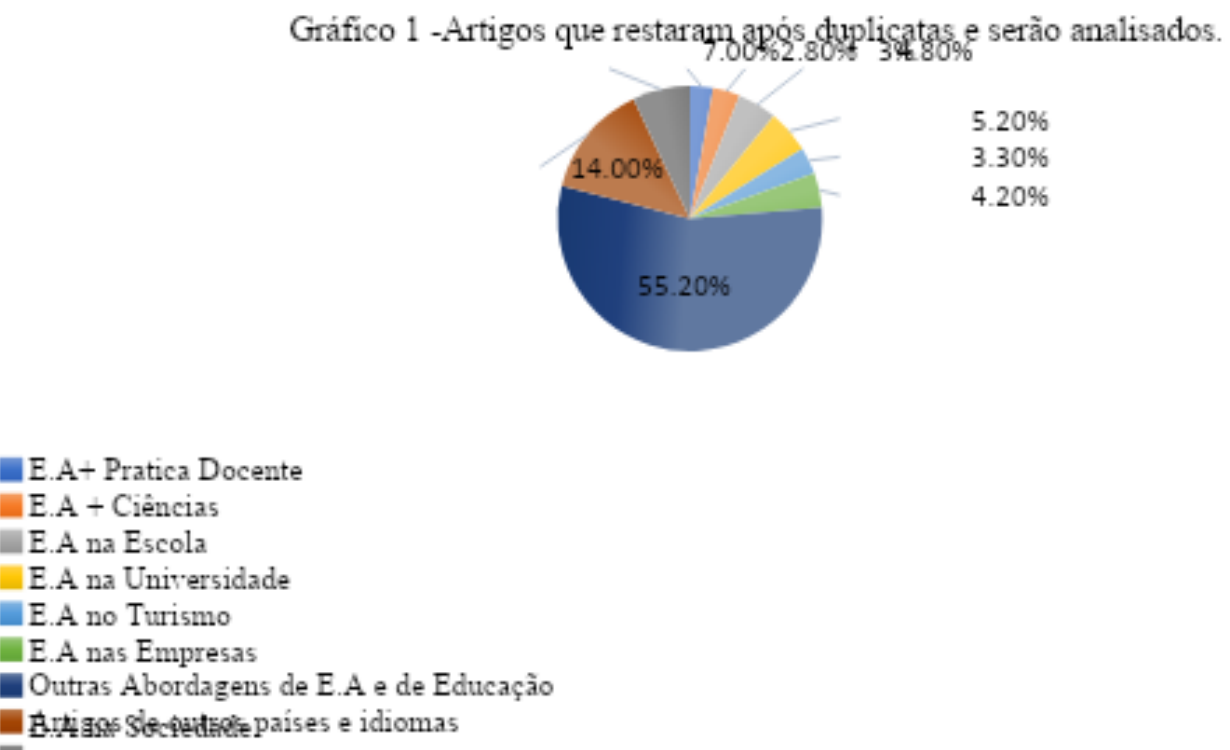

Fonte: Elaborado pelo próprio autor (2020) / Legenda: E.A. =Educação Ambiental.

- Após essa análise foram eliminados 796 artigos, sobrando para uma análise do artigo por completo 112 artigos. 
Desses 796 eliminados, é perceptível que as suas abordagens da temática ambiental ocorrem em diversas áreas, como dentro das empresas e no turismo, com uma visão da educação ambiental, muito mais conservacionista, sempre em busca de uma sustentabilidade, sem a visão da sociedade e natureza atuando juntas.

Outro ponto relevante dessa primeira análise, após a eliminação dos duplicados, foi o número de artigos que não foram realizados no Brasil e como o foco do estudo era como a educação ambiental é abordada no ensino fundamental nas aulas de ciências no Brasil, foi necessário excluí-los.

- Desses 112 artigos, foi realizada uma análise por completo, com a leitura do artigo inteiro e com muito rigor na análise dos dados, utilizando os critérios de inclusão e exclusão. Pois quando é realizado um estado da arte com artigos é necessária essa análise do artigo completo, para um rigor metodológico na pesquisa.

- Após esse rigor ao analisar os artigos, foram separados por temas abordados, conforme o gráfico 2 abaixo.

GrÁFICO 2: ANÁLISE DOS ARTIGOS COMPLETOS

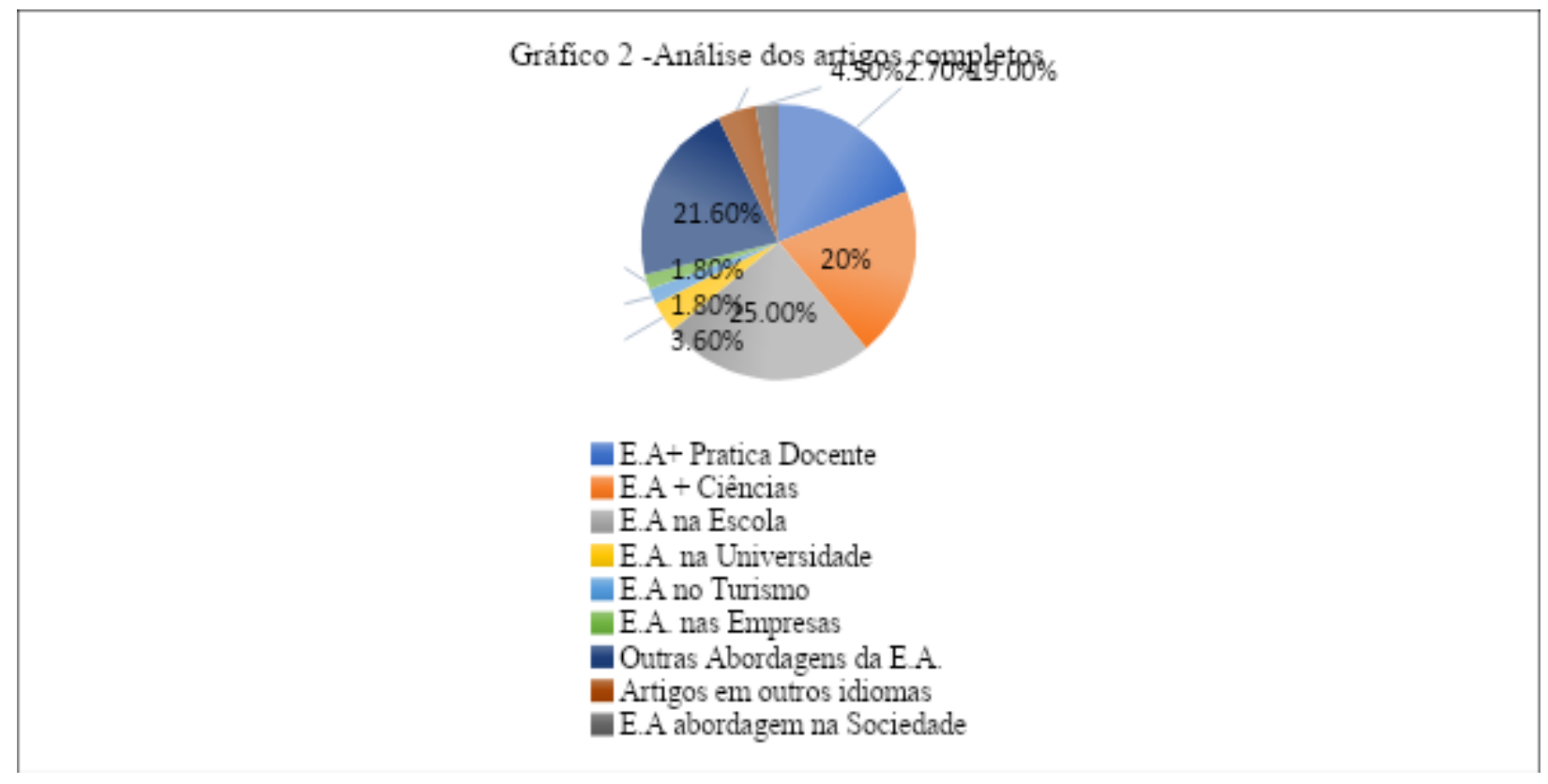

Fonte: Elaborado pelo autor (2020) / Legenda: E.A. =Educação Ambiental.

- Eliminados após análise completa dos artigos, restaram: 71 artigos

Com a análise dos artigos por inteiro, ficou evidente que a maioria abordava o assunto do qual o estudo pretende analisar, sendo eles a educação ambiental na prática docente, no ensino de ciências e dentro da escola, e em segundo lugar as outras abordagens da educação ambiental, que 
incluiu artigos que discutiam temas como a escassez da água, políticas ambientais e alguns com o uso da palavra ambiental em sentidos diversos.

Portanto, após essa análise detalhada do desenvolvimento dos artigos e suas metodologias, foram excluídos aqueles que não se integravam aos critérios de inclusão do estado da arte. Com isso foram selecionados os 41 artigos finais para a elaboração do estudo. Como é possível visualizar no gráfico 3, foram separados a partir dos temas que pertenciam ao critério de inclusão para o estudo, sendo esses os artigos finais selecionados.

\section{GRÁFICO 3: ARTIGOS FINAIS}

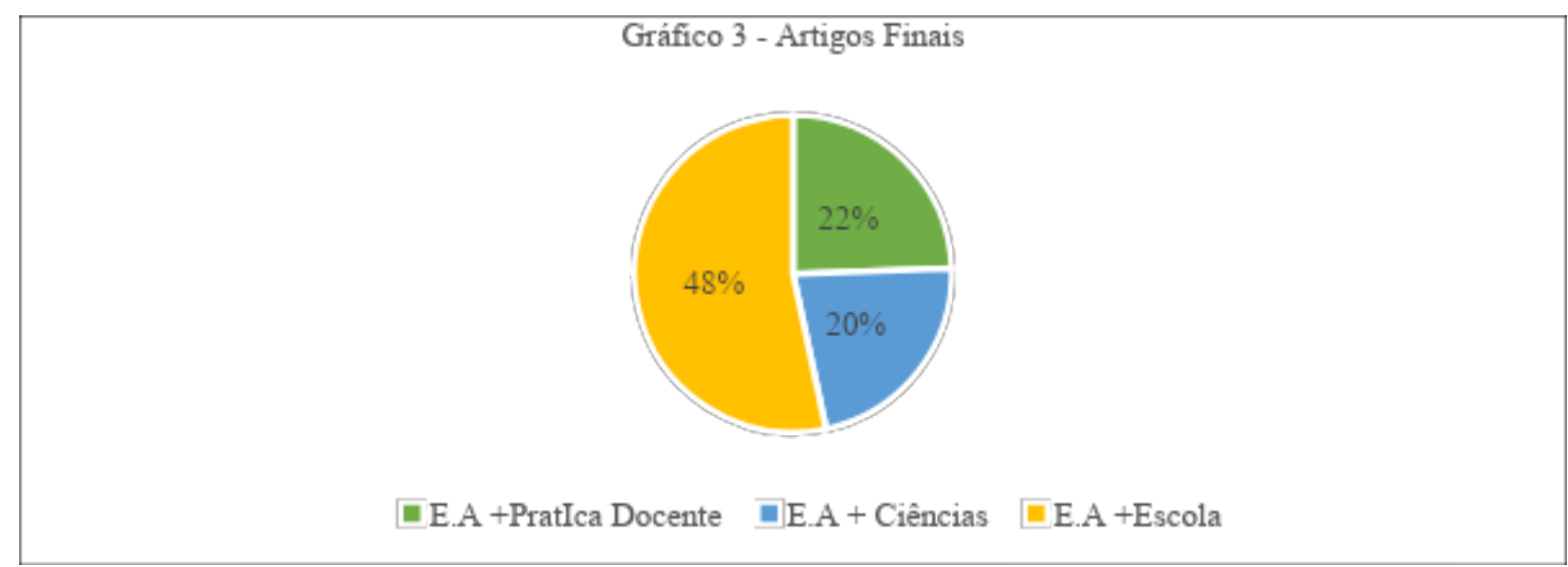

Fonte: Elaborado pelo próprio autor (2020) / Legenda: E.A. =Educação Ambiental.

\section{CONSIDERAÇÕES FINAIS}

Em um estudo do tipo estado da arte, são realizados levantamentos das perspectivas da área de conhecimento estudada, com a finalidades de diagnosticar quais são as temáticas estudadas, relevantes e recorrentes, auxiliando assim em novos estudos dentro da mesma área, e para o próprio pesquisador aprofundar seu conhecimento e organizar as suas informações sobre o seu tema de estudo. Como cita a autora Romanowisk (2002), “o estado da arte tem por objetivo realizar levantamentos do que se conhece sobre um determinado assunto a partir de pesquisas realizadas em uma determinada área".

A análise do conteúdo dos 41 artigos finais, encontrados nas bases SCIELO e REDALYC, que abordavam sobre a temática da educação ambiental no ensino de ciências nos anos de ensino fundamental, no Brasil, permitiu a identificação de uma preocupação, com a pouca produção acadêmica nessa área, na preocupação com a prática docente dentro da temática ambiental para o alunos do ensino fundamental, que estão em uma faixa etária de início do desenvolvimento crítico e reflexivo. 
Com a análise dos artigos finais, é possível perceber que a maioria deles atua muito mais na formação desse professor após o seu término da graduação, como um enfoque da temática ambiental, para que possam assim atuar em sala de aula, isso é colocado nos artigos até para professores da disciplina de ciências que realizam a formação continuada dentro dessa temática.

Outro detalhe muito importante de ressaltar, é o quão vasta é a percepção da educação ambiental dentro da corrente conservacionista, como cita a autora SAUVÉ (2005, p.20) "a preocupação com a administração do meio ambiente". Atividades centradas dentro de programas como os três "R", a escassez da água, ou em visitas a unidades de conservação guiadas por educadores ambientais, os quais abordam muito sobre a conservação e preservação daquele ambiente.

É possível ainda perceber que há uma prática muito comum da educação ambiental, analisada nos artigos da corrente naturalista, conforme SAUVÉ $(2005$, p. 18) “é centrada na relação com a natureza. O enfoque educativo pode ser cognitivo, experiencial, afetivo, espiritual ou artístico." São aqueles trabalhos, que atuam na construção de hortas, ou de trabalharem sobre os problemas do meio ambiente e como solucioná-los.

E quando se busca uma abordagem com o enfoque mais no socioambiental nos artigos, é perceptível o quão pouco é trabalhada a educação ambiental nessa percepção, de que o homem faz parte do meio ambiente, que ambos vivem em um ambiente em comum.

Outro detalhe de relevância nos artigos é que uma minoria observa, ou estuda a concepção do ponto de vista do professor de ciências dessa temática. Outra questão que não é analisada é a percepção interdisciplinar dentro da educação ambiental. Por isso é importante sempre desenvolver estudos de revisão para perceber quais são as necessidades de cada área.

Estudos como estado da arte podem constituir uma enorme contribuição dentro de um campo teórico de uma área de conhecimento, com o objetivo de identificar aporte de significância durante a elaboração da teoria e prática pedagógica, além de demonstrar os limites que há no campo em que a pesquisa caminha, indicar experiências inovadoras e o reconhecimento de contribuições dentro da área.

Finalmente, entre os diversos artigos analisados, é possível compreender a necessidade na produção acadêmica dentro da área, com uma união dentro das escolas, nas abordagens mais transversais com a visão mais crítica e reflexiva do meio ambiente junto a sociedade, pois ambos se pertencem.

Acredito que este trabalho, será ampliado e aprofundado. Além de enfatizar a necessidade de se ampliar, estimular e diversificar a pesquisa em educação ambiental, dentro das escolas, com uma visão mais crítica e de reflexão socioambiental. 


\section{REFERÊNCIAS BIBLIOGRÁFICAS}

CARVALHO, I. Educação Ambiental a formação do sujeito ecológico. Cortez. São Paulo/SP. $6^{\text {a }}$ edição. 2012.

DELORS, J. Educação: um tesouro a descobrir. Relatório UNESCO da Comissão Internacional sobre Educação para o século XXI. Relatório. São Paulo. Cortez Editora; Brasília. MEC/UNESCO. 2001, 288p.

PENTEADO, Heloísa Dupas. Meio Ambiente e Formação de Professores. $7^{\mathrm{a}}$ ed. São Paulo: Cortez, 2010.

ROMANOWSKI, Joana Paulin. As licenciaturas no Brasil: um balanço das teses e dissertações dos anos 90. Tese (Doutorado) - Faculdade de Educação da Universidade de São Paulo, São Paulo, 2002.

SAUVÉ, L. Uma cartografia das correntes em educação ambiental. In: SATO, M.; CARVALHO, I. Educação Ambiental Pesquisa e Desafios. Artmed. São Paulo/SP. 2005

\section{ANEXO}

Listamos a seguir os 41 artigos encontrados na pesquisa:

ABREU, D.; CAMPOS, M.; AGUILAR, M. Educação ambiental nas escolas da região de Ribeirão Preto (SP): Concepções orientadoras da prática docente e reflexões sobre a formação inicial de professores de química. Quim. Nova, v. 31, n. 3, p. 688-693, 2008.

BAGNOLO, C. Empresariado e ambiental: Algumas considerações sobre a educação ambiental no espaço escolar. Ciência \& Educação. Bauru/SP, v. 16, n. 2, p. 401-413, 2010.

BAIERL, O. A Ciência, a Natureza da Ciência e o Ensino de Ciências. Ciênc. Educ., Bauru/SP, v. 25, n. 4, p. 851-854, 2019.

BASSOLI, F.; LOPES, J.G; TEIXEIRA, C. Reflexões sobre experiências de formação continuada de professores em um centro de ciências: trajetória, concepções e práticas formativas. Ciência \& Educação (Bauru), v. 23, n. 4, outubro-dezembro, p. 817-834, 2017.

BATISTA, D.; SHITASUKA, R. Ensino de ciências: um estudo de alinhamento de conteúdos no ensino fundamental. Research, Society and Development, v. 8, n. 1, 2019.

BATISTA, K.; TAVARES, B. Educação Ambiental no Contexto Escolar: Ressignificando Práticas. Research, Society and Development, v. 8, n. 1, 2019.

BONOTTO, D.; SEMPREBONE, A. Educação ambiental e educação em valores em livros didáticos de ciências naturais. Ciência \& Educação. Bauru/SP, v. 16, n. 1, p. 131-148, 2010.

BORGES, T.; COSTA, R.; OLIVEIRA, V.; GONTIJO, H. BIOEDUCA: Educação ambiental nos anos iniciais do ensino fundamental. Research, Society and Development, v. 8, n. 3, 2019.

CARDOSO, N. A contribuição do bibliotecário para a educação ambiental. Perspectivas em Ciência da informação, v. 15, n. 2, p. 140-162, maio. /ago. 2010. 
COELHO, G.; CARVALHO, V.; Atividades em um centro de ciências: motivos estabelecidos por educadores, suas concepções e articulações com a escola. Educação e Pesquisa, v. 42, n. 2, abril-junho, p. 525-538, 2016.

COSTA, C.; LOUREIRO, C. A interdisciplinaridade em Paulo Freire: aproximações político-pedagógicas para a educação ambiental crítica. Revista Katálysis, v. 20, n. 1, p. 111-121 2017.

DANTAS, O.; NAKAYAMA, L. Teatro de fantoches na formação continuada docente em educação ambiental. Educação e Pesquisa, São Paulo/SP, v. 38, n. 3, p. 711-726, jul./set. 2012.

DA SILVA, S. Educação ambiental escolar: Estudando teorias e visualizando iniciativas realizadas no colégio módulo em Juazeiro do Norte -CE. Revista de Estudos Geoeducacionais, vol. 6, núm. 3, p. 16-26, 2015.

FREITAS, N.; GONÇALVES, T. Práticas teatrais e o ensino de Ciências: o teatro jornal na abordagem da temática do lixo. Educar em Revista, n. 68, p. 199-216, 2018.

GOMES, R.; NAKAYAMA, L. Educação Ambiental: saberes necessários a práxis educativa docente de uma escola amazônica amapaense. Educar em Revista, n. 66, p. 257-273, out./dez. 2017.

GUIMARÃES, S.; INFORSATO, E. A Percepção do professor de biologia e a sua formação: A educação ambiental em questão. Ciência \& Educação, v. 18, n. 3, p. 737-754, 2012.

IARED, V.; OLIVEIRA, H. Concepções de educação Ambiental e perspectivas pedagógicas de professora do ensino fundamental. Educação em Revista. Belo Horizonte/ MG. v. 27, n. 2, p. 95-122, ago. 2011

KONDRAT, H.; MACIEL, M. Educação ambiental para a escola básica: contribuições para o desenvolvimento da cidadania e da sustentabilidade. Revista Brasileira de Educação, v. 18, n. 55, p. 825-846, 2013.

LEIRI, V.; SANTANA, L. Concepções e prática de educação ambiental de professores de uma escola pública. Ciência \& Educação, v. 16, n. 2, p. 387-399, 2010.

LIMA, A. M.; OLIVEIRA, H. A (RE) Construção dos conceitos de natureza, meio ambiental e educação ambiental por professores de duas escolas públicas. Ciência \& Educação, v. 17, n. 2, p. 321-337, 2011.

MARPICA, N.; LOGAREZZI, J. Um panorama das pesquisas sobre livro didático e educação ambiental. Ciência \& Educação, v. 16, n. 1, p. 115-130, 2010.

MARTINS, J.; SCHNETZLER, R. Formação de professores em educação ambiental crítica centrada na investigação-ação e na parceria colaborativa. Ciência \& Educação, v. 24, n. 3, julho-setembro, p. 581-598, 2018.

MOTOKANE, M. Sequências didáticas investigativas e argumentação no ensino de ecologia. Ensaio Pesquisa em Educação em Ciências, v. 17, p. 115-137, 2015.

NASCIMENTO, C.; ANJOS, M.; VASCONCELOS, S. Pesquisa-ação e triangulação metodológica na investigação de percepções de um grupo de alunos da educação básica sobre o ambiente. Ensaio Pesquisa em Educação em Ciências, v. 20, 2018.

NETO, A.L.; AMARAL, E. Ensino de ciências e educação ambiental no nível fundamental: Análise de algumas estratégias didáticas. Ciência \& Educação, v. 17, n. 1, p. 129-144, 2011. 
NIGRO, R.; AZEVEDO, M. Ensino de ciências no fundamental 1: Perfil de um grupo de professores em formação continuada num contexto de alfabetização científica. Ciências \& Educação, Bauru/SP, v. 17, n. 3, p. 705-720, 2011.

OLIVEIRA, V.; SILVA, P.A educação ambiental na sociedade atual: Uma experiência na rede escolar. Research, Society and Development, v. 8, n. 4, 2019.

PELEGRINI, D.; VLACH, V. As múltiplas dimensões da educação ambiental: por uma ampliação da abordagem. Soc. \& Nat.v. 23, n. 2, p. 187-196, maio/ago. 2011.

PEREIRA, G.; MASCARENHAS, L. Formação continuada de professores dos anos iniciais da educação básica: impacto do programa formativo de um museu de ciência a partir do viés crítico-reflexivo. Ensaio Pesquisa em Educação em Ciências, v. 19, p. 1-22, 2017.

PEREIRA, R.; COSTA, R. Educação Ambiental por meio de horta comunitária: Estudo em uma escola pública da cidade de São Paulo. Revista Científica Hermes, v. 16, p. 246-270, 2016.

RODRIGUES, A. Educação Ambiental em tempos de transição paradigmática: Entrelaçando saberes "disciplinados". Ciência \& Educação. Bauru/SP, v. 20, n. 1, p. 195-206, 2014.

RODRIGUES, D.; LEITE, R. Para além do espaço verde na escola: análise das concepções sobre educação ambiental vinculadas à proposta da Mostra de Educação Ambiental no Ceará. Ciênc. Educ., v. 23, n. 3, p. 643-657, 2017.

RODRIGUES, D. G.; SAHEB, D A formação continuada do professor de Educação Infantil em Educação Ambiental. Ciênc. Educ., Bauru, v. 25, n. 4, p. 893-909, 2019.

SILVA, R. Leitura de imagens da mídia e educação ambiental: Contribuições para a formação de professores. Educação em Revista. Belo Horizonte/MG, v. 26, n. 2, p. 277-298, ago. 2010.

SILVA, D.; FOLMER, V.; PUNTEL, L. Concepções de professoras de Ciências sobre o ensino de Ciências. Revista Exitus, v. 7, n. 2, p. 237-261, 2017.

SILVA, S.; MANFRINATO, M.; ANACLETO, T. Morcegos: Percepção dos alunos do ensino fundamental $3^{\circ}$ e $4^{\circ}$ ciclos e práticas de educação ambiental. Ciências e Educação, v. 19, n. 4, p. 859-877, 2013.

TORALES, M.; TEIXEIRA, C. A questão ambiental e a formação de professores para a educação básica: um olhar sobre as licenciaturas. Educar em Revista, Edição Especial n. 3, p. 127-144, 2014.

TOZONI-REIS, M., A Inserção da educação ambiental na educação básica: que fontes de informação os professores utilizam para a sua formação?. Ciênc. Educ., v. 19, n. 2, p. 359-377, 2013.

TOZONI-REIS, M.; CAMPOS, L. Educação ambiental escolar, formação humana e formação de professores: articulações necessárias. Educar em Revista, Edição Especial n. 3, p. 145-162, 2014.

TULLIO, A.; HOFSTATTER, J. O potencial formativo dos grupos focais na constituição de educadoras/es ambientais. Ciência e Educação, v. 25, n. 2, p. 411-429, 2019.

XISTO, D.; CHAPANI, T. A Pesquisa na formação em exercício de professores de ciências e biologia. Ensaio Pesquisa em Educação em Ciências, v. 19, p. 1-19, 2017. 